\title{
KEBIJAKAN FULL DAY SCHOOL TERHADAP PERKEMBANGAN SOSIAL ANAK USIA DINI DI TK LASIYAM KOTA
}

\author{
Retno Riski Wardhani ${ }^{1}$, Wahono $^{2}$, Tri Kurniawati ${ }^{3}$ \\ Universitas Muhammadiyah Surabaya \\ Email:wardhani314@gmail.com¹,wwwahono7@gmail.com², \\ trikurniawati@fkip.um-surabaya.ac.id ${ }^{3}$
}

\begin{abstract}
Abstrak
Full day school merupakan sistem sekolah sehari penuh yang dimana dalam sistem pembelajaran di sekolah ini untuk mempermudah para orang tua memonitori anak dalam perkembangan pendidikannya. Full day school ini orang tua merasa aman, setiap lingkup bermainnya hanya sekitar pada lingkungan sekolahnya. Sistem full day school juga melatih anak dalam perkembangan sosialnya antara lain melatih dalam kemandirian, tanggung jawab, serta kedisiplinan. Guru juga berperan aktif dalam pembentukan perkembangan yang ada dalam anak usia dini, karena sebagian besar waktu mereka berada di sekolah, selain guru orang tua juga ikut serta dan berperan penuh dalam membentuk perkembangan sosial anak. Tujuan peneliti ini untuk mengetahui perubahan perkembangan sosial yang ditimbulkan pada sistem full day school. Metode yang digunakan dalam penelitian ini adalah metode deskriptif kualitatif yang mana menggunakan teknik observasi, wawancara dan dokumentasi. Subjek penelitiannya adalah beberapa anak didik beserta guru kelas kelompok B di TK Lasiyam Kota Surabaya. Pengamatan yang dilakukan lebih terhadap perkembangan sosial yang ada pada full day school, dalam sistem pendidikan full day school anak mengalami perkembangan sosial yang signifikan terutama pada kemandirian, kedisiplinan dan tanggung jawabnya, yang didukung pada stimulus yang diberikan pada lingkungan sekolah, sehingga anak memiliki perkembangan sosial yang baik.
\end{abstract}

\section{Kata kunci : full day school; perkembangan sosial; anak usia dini}

\begin{abstract}
Full day school is a full day school system which is in the learning system in this school is used to make it easier for parents to monitor children in the development of education. Full day school parents feel safe, every scope of play just around the school environment. The full day school system also trains children in their social development such as training in independence, responsibility, and discipline. Teachers also play an active role in shaping the development that exists in early childhood, because they are in school most of the time, besides the teachers, parents also participate and play a role in shaping the social development of children. The purpose of the researcher is to know the social development changes caused in full day school system. The method used in this research is descriptive qualitative method which used observation technique, interview and documentation. Research subjects are some students and classroom teachers B in TK Lasiyam Surabaya. The observations made more on the social developments that exist in full day school, in the system of full day school education of children experiencing significant social development, especially on independence, discipline and responsibility, supported on the stimulus given to the school environment, so that children have social development the good one.
\end{abstract}

Keywords: Full Day School; Social Development; Early Childhood

\section{PENDAHULUAN}

Pendidikan adalah sebuah proses pengubahan sikap dan tingkah laku seseorang atau sekelompok orang untuk mendewasakan manusia dalam sebuah pembelajaran

(KBBI,1991:232:4). Menurut 
Poerbakawatja dan Harahap (1981:6) pendidikan merupakan suatu usaha secara sengaja dan orang dewasa untuk meningkatkan pengaruh kepada anak untuk proses kedewasaan yang diartikan mampu menimbulkan tanggung jawab moral dari segala perbuatannya. Pendidikan merupakan dimensi yang sangat penting dari kehidupan anak (Marrison, 2006; Santrock, 2006a).

Undang-Undang Nomer 20

Tahun 2003 menyatakan tentang Sistem Pendidikan Nasional disebutkan bahwa pendidikan adalah usaha dasar dan terencana untuk mewujudkan suasana belajar dan proses pembelajaran agar peserta didik secara aktif dapat mengembangkan potensi dirinya untuk memiliki kekuatan spiritual keagamaan, pengenalan diri, kepribadian, kecerdasan, akhlak mulia serta keterampilan yang diperlakukan dirinya, masyarakat, bangsa dan negara. Pendidikan anak usia dini dapat diselenggarakan melalui jalur formal, nonformal dan informal. Sekolah merupakan lembaga pendidik formal yang diharapkan untuk memenuhi kualitas kebutuhan masyarakat.

Fullday school adalah sebuah sistem pendidikan yang dimana pembelajarannya dimulai dari pagi sampai sore hari atau satu hari pembelajaran. Sistem fullday school sebenarnya memiliki kurikulum inti yang sama dengan sekolah lainnya, dengan sistem pembelajaran yang menekankan pada nilai kemandirian siswa.
Pembelajaran dengan sistem full day school dimana untuk memenuhi mobilitas hidup yang di mana kebutuhan akan masyarakat sekarang sibuk dengan dunia kerja. Orang tua juga ingin pendidikan yang berkualitas bagi anaknya. Konsep pendidikan dengan sistem pendidikan full day school di mana yang saat ini masih menjadi perdepatan didunia pendidikan, yang mana anak akan kehilangan waktu bermain di luar rumah dan jadwal yang padat akan membuat jenuh. Disisi lain, siswa akan mendapatkan pendidikan yang bervariasi sehingga berbeda dengan pendidikan sekolah lain atau reguler. Sistem pembelajaran full day school juga menanamkan nilai-nilai yang posistif bagi anak.

Adapun tujuan penelitian ini adalah (1) Untuk mengetahui perkembangan sosial anak usia 5-6 tahun yang ada di TK Lasiyam Kota Surabaya; (2) Mendeskripsikan sistem pelaksanaan full day schoolpada anak usia 5-6 tahun di TK Lasiyam Kota Surabaya; (3) Mendeskripsikan kebijakan full day school terhadap perkembangan anak usia 5-6 tahun di TK Lasiyam kota Surabaya.

\section{METODE PENELITIAN}

Penelitian ini menggunakan pendekatan kualitatif. Pada penelitian kualitatif, penelitian yang menggunakan latar alamiah, dengan maksud menafsirkan fenomena yang terjadi dan dilakukan dengan jalan melibatkan berbagai metode yang 
ada menurut Dezin dan Lincoln (Moleong, 2007:5).

Penelitian dilakukan di TK Lasiyam kota Surabaya khusunya dikelompok TK B. Data yang dikumpulkan sebagai data primer adalah berupa observasi dan wawancara yang berkaitan dengan kebijakan full day school terhadap perkembangan sosial anak usia dini di TK Lasiyam kota Surabaya. tujuan, sasaran, latar belakang, efektifitas, efisiensi dan progres dari Program-program sekolah yang berkaitan dengan usaha mendorong perkembangan sosial peserta didik di TK Lasiyam Kota Surabaya. Adapun data tersebut akan diperoleh dari wawancara dengan guru kelas kelompok B, sedangkan pengumpulan data akan dilakukan dengan wawancara, pengamatan atau observasi.

Berikut ini data tabel sosial berserta deskripsi dan data tabel observasi yang diperincikan dari butir pertanyaan observasi sebagai berikut :

Tabel 1. Sosial Beserta Deskripsi Bagi Anak

\begin{tabular}{|ll|ll|}
\hline \multicolumn{2}{|c|}{ Nilai } & \multicolumn{1}{|c|}{ Deskripsi } \\
\hline $\begin{array}{l}\text { 1. } \\
\begin{array}{l}\text { Memiliki perilaku yang } \\
\text { mencerminkan } \\
\text { mandiri }\end{array}\end{array}$ & $\begin{array}{l}\text { Perilaku yang mencerminkan sikap mandiri terhadap } \\
\text { dirinya sendiri }\end{array}$ \\
\hline 2. & $\begin{array}{l}\text { Memiliki perilaku yang } \\
\text { mencerminkan sikap dan } \\
\text { aturan sehari-hari dalam } \\
\text { kedisplinan }\end{array}$ & $\begin{array}{l}\text { Perilaku yang menunjukkan kedisiplinan dalam } \\
\text { kegiatan sehari-hari }\end{array}$ \\
\hline 3. & $\begin{array}{l}\text { Memiliki perilaku yang } \\
\text { mencerminkan } \\
\text { tanggung jawab sikap }\end{array}$ & $\begin{array}{l}\text { Perilaku yang mencerminkan sikap tanggung jawab } \\
\text { kepada barang miliknya }\end{array}$ \\
\hline 4. & $\begin{array}{l}\text { Memiliki kemampuan diri } \\
\text { untuk menyesuaikan } \\
\text { dengan situasi }\end{array}$ & $\begin{array}{l}\text { Memperlihatkan kemampuan diri } \\
\text { menyesuaikan dengan situasi }\end{array}$ \\
\hline
\end{tabular}

Tabel 2. Pedoman Penilaian Observasi

\begin{tabular}{|c|c|c|}
\hline No & Butir Pernyataan & Penilaian \\
\hline \multirow[t]{2}{*}{1} & $\begin{array}{l}\text { a. Melakukan Hal-hal sendiri (muda } \\
\text { bergaul atau tidak pilih-pilih teman) }\end{array}$ & $\begin{aligned} & \text { : Anak dapat melakukan hal-hal } \\
& \text { sendiri dengan mandiri dan berani } \\
3 & : \text { Anak mampu melakukan hal-hal } \\
& \text { sendiri dengan motivasi } \\
2 \quad: & \text { Anak mulai melakukan hal-hal } \\
& \text { sendiri dengan dorongan dan } \\
& \text { motivasi sekali } \\
1 \quad: & \text { Anak belum mau melakukan hal- } \\
& \text { hal sendiri }\end{aligned}$ \\
\hline & $\begin{array}{ll}\text { a. } & \begin{array}{l}\text { Membuat pilihan-pilihan } \\
\text { (memilih kegitan sendiri) }\end{array}\end{array}$ & $\begin{aligned} \text { : Anak dapat membuat pilihan- } \\
\text { pilihan dikelas dengan sendiri dan } \\
\text { mandiri }\end{aligned}$ \\
\hline
\end{tabular}




\begin{tabular}{|c|c|c|c|}
\hline & & & $\begin{array}{l}\text { :Anak mampu membuat pilihan- } \\
\text { pilihan dengan } 1 \text { kali bantuan } \\
\text { :Anak mulai membuat pilihan- } \\
\text { pilihan dengan motivasi } \\
\text { :Anak belum mau membuat pilihan- } \\
\text { pilihan dikelas }\end{array}$ \\
\hline & $\begin{array}{l}\text { b. Tidak tergantung dengan orang lain } \\
\begin{array}{l}\text { (mengambil bekal } \\
\text { perlengkapan pribadi) }\end{array}\end{array}$ & 4 & $\begin{array}{l}\text { :Anak dapat melakukan kegiatan } \\
\text { dengan mandiri } \\
\text { :Anak mampu melakukan kegiatan } \\
\text { dengan } 1 \text { kali bantuan } \\
\text { :Anak mulai melakukan kegiatan } \\
\text { dengan dorongan dan motivasi } \\
\text { :Anak belum melakukan kegiatan }\end{array}$ \\
\hline \multirow[t]{2}{*}{2} & 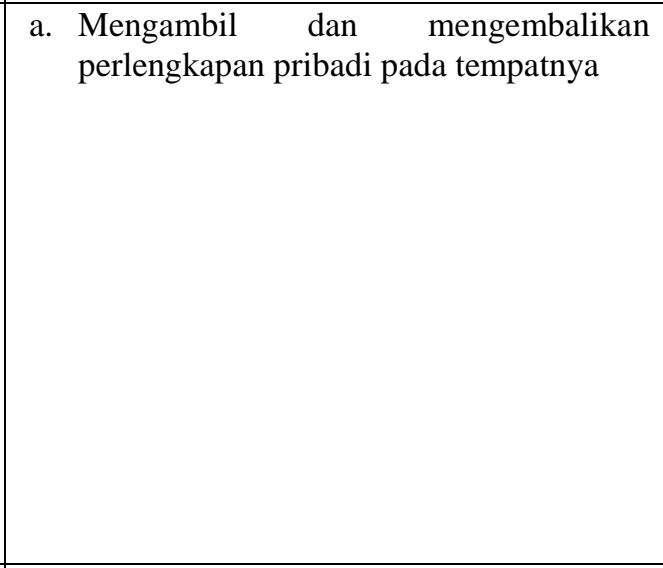 & 3 & $\begin{array}{l}\text { :Anak dapat } \\
\text { mengembalikan }\end{array} \begin{array}{lr}\text { perlengkapan } \\
\text { pribadi pada tempatnya dengan } \\
\text { mandiri dan tepat }\end{array}$ \\
\hline & b.Mengerjakan sesuatu hingga tuntas & 2 & $\begin{array}{l}\text { :Anak dapat mengerjakan sesuatu } \\
\text { hingga tuntas dengan tepat dan } \\
\text { mandiri } \\
\text { :Anak mampu mengerjakan sesuatu } \\
\text { hingga tuntas dan tepat } \\
\text { :Anak mampu mengerjakan sesuatu } \\
\text { hingga tuntas dengan motivasi } \\
\text { :Anak belum mau mengerjakan } \\
\text { sesuatu hingga tuntas }\end{array}$ \\
\hline \multirow[t]{2}{*}{3} & $\begin{array}{l}\text { a. Berpisah dengan orang tua tanpa } \\
\text { kesuliatan (berani masuk kelas) }\end{array}$ & 2 & $\begin{array}{l}\text { :Anak berani berpisah dengan orang } \\
\text { tua tanpa kesulitan dan mandiri } \\
\text { :Anak mampu berpisah dengan orang } \\
\text { tua dengan motivasi } \\
\text { :Anak mampu berpisah dengan orang } \\
\text { tua dengan bantuan } \\
\text { :Anak belum mau berpisah dengan } \\
\text { orang tua }\end{array}$ \\
\hline & $\begin{array}{llll}\text { b.Meminta } & \text { bantuan jika benar-benar } \\
\text { diperlukan } & & \end{array}$ & 2 & $\begin{array}{l}\text { :Anak dapat meminta bantuan } \\
\text { dengan percaya diri dan berani } \\
\text { :Anak mampu meminta bantuan } \\
\text { dengan motivasi } \\
\text { :Anak mulai meminta bantuan } \\
\text { dengan dorongan } \\
\text { :Anak belum meminta bantuan }\end{array}$ \\
\hline 4 & a.Menaati aturan bermain & 4 & $\begin{array}{l}\text { :Anak dapat menaati aturan bermain } \\
\text { dengan mandiri } \\
\text { :Anak mampu menaati aturan } \\
\text { bermain dengan motivasi } \\
\text { :Anak mampu menaati aturan } \\
\text { bermain dengan bantuan } \\
\text { : Anak belum menaati aturan bermain }\end{array}$ \\
\hline
\end{tabular}




\begin{tabular}{|l|l|l|}
\hline b.Cara mengatur diri sendiri & $4 \begin{array}{l}\text { :Anak dapat mengatur diri sendiri } \\
\text { dengan mandiri }\end{array}$ \\
& $3 \quad$ :Anak mampu mengatur diri sendiri \\
dengan motivasi \\
$2 \quad \begin{array}{l}\text { :Anak mampu mengatur diri sendiri } \\
\text { dengan arahan }\end{array}$ \\
& 1 :Anak belum mau mengatur diri \\
& sendiri \\
\hline
\end{tabular}

\section{HASIL PENELITIAN}

Hasil penelitian observasi dan wawancara terhadap anak beserta guru kelas kelompok B yang penuis anggap mampu untuk memberikan keterangan yang relevan, dilengkapi dengan dokumen yang ada. Mengacu pada fokus penelitian, maka penulis akan menganalisa dan menyajikannya secara sistematis tentang perkembangan sosial anak usia dini dalam full day school di TK Lasiyam. Berdasarkan hasil observasi yang dikumpulkan berkaitan dengan perkembangan sosial anak usia dini dalam full day school sebagai berikut :

Tabel 3. Penilain Pemahaman Tentang Mandiri

\begin{tabular}{|c|c|c|c|c|c|c|c|c|c|c|c|c|c|}
\hline \multirow{3}{*}{ No } & \multirow{3}{*}{ Responden } & \multicolumn{12}{|c|}{ Pemahaman Tentang Mandiri } \\
\hline & & \multicolumn{4}{|c|}{$\mathbf{A}$} & \multicolumn{4}{|c|}{ b } & \multicolumn{4}{|c|}{ c } \\
\hline & & 4 & 3 & 2 & 1 & 4 & 3 & 2 & 1 & 4 & 3 & 2 & 1 \\
\hline 1 & Responden 1 & & & $\sqrt{ }$ & & & & $\sqrt{ }$ & & & & $\sqrt{ }$ & \\
\hline 2 & Responden 2 & & & $\sqrt{ }$ & & & & $\sqrt{ }$ & & & & & $\sqrt{ }$ \\
\hline 3 & Responden 3 & $\sqrt{ }$ & & & & $\sqrt{ }$ & & & & $\sqrt{ }$ & & & \\
\hline 4 & Responden 4., & $\sqrt{ }$ & & & & & $\sqrt{ }$ & & & $\sqrt{ }$ & & & \\
\hline 5 & Responden 5 & $\sqrt{ }$ & & & & & $\sqrt{ }$ & & $\sqrt{ }$ & & & & \\
\hline 6 & Responden 6 & $\sqrt{ }$ & & & & $\sqrt{ }$ & & & $\sqrt{ }$ & $\sqrt{ }$ & & & \\
\hline 7 & Responden 7 & $\sqrt{ }$ & & & & $\sqrt{ }$ & & & & & $\sqrt{ }$ & & \\
\hline & Jumlah & 5 & & 2 & & 3 & 2 & 2 & 2 & 3 & 1 & 1 & 1 \\
\hline
\end{tabular}

\section{Keterangan :}
a : Melakukakan hal-hal sendiri
b : Membuat Pilihan-pilihan dikelas
c : Tidak Tergantung Orang Lain 
Tabel 4. Penilain Pemahaman Tanggung Jawab

\begin{tabular}{|c|c|c|c|c|c|c|c|c|c|}
\hline \multirow{3}{*}{ No } & \multirow{3}{*}{ Responden } & \multicolumn{8}{|c|}{ Pemahaman Tanggung Jawab } \\
\hline & & \multicolumn{4}{|c|}{$\mathbf{a}$} & \multicolumn{4}{|c|}{ b } \\
\hline & & 4 & 3 & 2 & 1 & 4 & 3 & 2 & 1 \\
\hline 1 & Responden 1 & & $\sqrt{ }$ & & & & & $\sqrt{ }$ & \\
\hline 2 & Responden 2 & & $\sqrt{ }$ & & & & $\sqrt{ }$ & & \\
\hline 3 & Responden 3 & $\sqrt{ }$ & & & & $\sqrt{ }$ & & & \\
\hline 4 & Responden 4 & $\sqrt{ }$ & & & & $\sqrt{ }$ & & & \\
\hline 5 & Responden 5 & $\sqrt{ }$ & & & & $\sqrt{ }$ & & & \\
\hline 6 & Responden 6 & $\sqrt{ }$ & & & & $\sqrt{ }$ & & & \\
\hline 7 & Responden 7 & $\sqrt{ }$ & & & & $\sqrt{ }$ & & & \\
\hline & Jumlah & 5 & 2 & & & 5 & 1 & 1 & \\
\hline
\end{tabular}

\section{Keterangan :}

a : Mengambil dan merapikan kembali perlengkapan pribadi pada tempatnya

b : Mengerjakan sesuatu hingga tuntas

Tabel 5. Penilain Menunjukkan Sikap Positif dan Disiplin

\begin{tabular}{|c|c|c|c|c|c|c|c|c|c|c|c|c|c|c|c|c|c|}
\hline \multirow{3}{*}{ No } & \multirow{3}{*}{ Responden } & \multicolumn{8}{|c|}{ Menunjukkan Sikap Positif } & \multicolumn{8}{|c|}{ Pemahaman Tentang Disiplin } \\
\hline & & \multicolumn{4}{|c|}{$\mathbf{A}$} & \multicolumn{4}{|c|}{ b } & \multicolumn{4}{|c|}{$\mathbf{a}$} & \multicolumn{4}{|c|}{ B } \\
\hline & & 4 & 3 & 2 & 1 & 4 & 3 & 2 & 1 & 4 & 3 & 2 & 1 & 4 & 3 & 2 & 1 \\
\hline 1 & Responden 1 & $\sqrt{ }$ & & & & & & $\sqrt{ }$ & & & & & $\sqrt{ }$ & & & $\sqrt{ }$ & \\
\hline 2 & Responden 2 & & & & $\sqrt{ }$ & & & $\sqrt{ }$ & & & $\sqrt{ }$ & & & & & & $\sqrt{ }$ \\
\hline 3 & Responden 3 & $\sqrt{ }$ & & & & $\sqrt{ }$ & . & & & $\sqrt{ }$ & & & & $\sqrt{ }$ & & & \\
\hline 4 & Responden 4 & $\sqrt{ }$ & & & & $\sqrt{ }$ & & & & & $\sqrt{ }$ & & & $\sqrt{ }$ & & & \\
\hline 5 & Responden 5 & $\sqrt{ }$ & & & & & $\sqrt{ }$ & & & $\sqrt{ }$ & & & & & $\sqrt{ }$ & & \\
\hline 6 & Responden 6 & $\sqrt{ }$ & & & & $\sqrt{ }$ & & & & $\sqrt{ }$ & & & & $\sqrt{ }$ & & & \\
\hline 7 & Responden 7 & $\sqrt{ }$ & & & & $\sqrt{ }$ & & & & $\sqrt{ }$ & & & & $\sqrt{ }$ & & & \\
\hline & Jumlah & 6 & & & 1 & 4 & 1 & 2 & & 4 & 2 & & 1 & 4 & 1 & 1 & 1 \\
\hline
\end{tabular}

1) Keterangan menunjukkan sikap positif terhadap diri sendiri dan orang lain

a : Berpisah dengan orang tua tanpa kesulitan

b : Meminta bantuan jika benar-benar diperlukan

2) Keterangan pemahaman tentang disiplin

$\mathrm{a}:$ Menaati aturan bermain 
$\mathrm{b}:$ Cara mengatur diri sendiri

Berdasarkan dari data tabel penilaian di atas perkembangan sosial dari tujuh responden kelompok B, sudah dikatakan berkembang dengan baik dengan hasil penilaian yang rata-rata mendapatkan bintang . Indikator yang terdapat beberapa butir dalam pemahaman tentang mandiri yaitu, melakukan hal-hal sendiri, membuat pilihan-pilihan dikelas, tidak tergantung pada orang lain. Sebagian dari tujuh responden tersebut sudah mandiri dan dapat melakukannya dengan baik, dari hasil penelitian beberapa anak yang masih memerlukan bantuan dan motivasi dalam hal kemandirian, seperti berani masuk kelas sendiri, cara mengatur diri sendiri, ananda masih perlu diantar saat masuk kedalam kelas.

\section{PEMBAHASAN}

Subjek penelitian adalah murid kelompok B usia 5-6 tahun di TK Lasiyam Kota Surabaya, Objek dalam penelitian ini adalah perkembangan sosial anak usia 5-6 tahun yang dimana dalam perkembangan sosial anak memiliki sikap tanggung jawab, mandiri, disiplin dan berani kesekolah sendiri. Perkembangan sosial yang dialami oleh anak usia 5-6 tahun dimana anak memiliki sikap menaati aturan, percaya diri, sabar, mandiri, suka menolong, tanggung jawab, jujur, sopan santun kepada orang tua.

Berdasarkan data-data dari hasil penelitian tentang penerapan perkembangan sosial Kelompok B di TK Lasiyam Kota Surabaya dengan subyek penelitian tujuh responden dan dengan empat indikator tentang perkembangan sosial, dimana setiap indikator ada tiga butir penilaian. Penilaian berupa bintang satu, bintang dua, bintang tiga, bintang empat. Berikut penjelasan rinci tiaptiap indikator.

a. Pemahaman tentang mandiri

Pada indikator pemahaman tentang mandiri dalam butir melakukan hal-hal sendiri ada 5 anak yang mendapatkan bintang 4, dan 2 anak mendapatkan bintang 2. Membuat pilihan-pilihan dikelas ada 3 anak yang mendapatkan bintang 4, dan 2 anak mendapatkan bintang 3, untuk bintang 2 ada 2 anak yang mendapatkannya. Tidak tergantung dengan orang lain ada 3 anak yang mendapatkan bintang 4, ada 1 anak mendapatkan bintang 3, dan 1 anak mendapatkan bintang 2, 1 anak lagi mendapatkan bintang 1. Anak mendapatkan bintang 4 anak mampu dengan sendiri, untuk bintang 3 anak mampu dengan sendiri dan motivasi, untuk bintang 2 anak mampu dengan sendiri dan bantuan, dan untuk bintang 1 anak belum mau melakukannya. Jadi pada indikator pemahaman tentang mandiri pada keseluruhan butir-butir tersebut 
anak sudah bisa mandiri dalam melakukan hal-hal sendiri, tidak tergantung dengan orang lain dan beberapa anak masih memerlukan bantuan dalam tidak tergantung dengan orang lain.

b. Pemahaman tentang tanggung jawab

Pada indikator pemahaman tentang tnggung jawabdalam butir mengambil dan merapikan kembali perlengkapan pribadi pada tempatnya ada 5 anak yang mendapatkan bintang 4 , dan 2 anak mendapatkan bintang 3 . Mengerjakan sesuatu hingga tuntas ada 5 anak mendapatkan bintang 4, 1 anak mendapatkan bintang 3 dan 1 anak lagi mendapatkan bintang 1. Anak mendapatkan bintang 4 anak mampu tanggung jawab dengan baik, untuk bintang 3 anak mampu tanggung jawab dengan motivasi, bintang 2 anak mampu dengan bantuan, untuk bintang 1 anak belum bisa bertanggung jawab. Jadi pada indikator pemahaman tentang tanggung jawab pada keseluruhannya anak sudah menunjukkan rasa tanggung jawabnya dalam mengambil dan merapikan perlengkapan pribadi pada tempatnya, mengerjakan sesuatu hingga tuntas dan sebagian masih perlu bantuan dan motivasi dalam mengerjakan sesuatu hingga tuntas. c. Menunjukkan sikap positif terhadap diri sendiri dan orang lain

Pada indikator menunjukkan sikap positif terhadap diri sendiri dan orang lain dalam butir berpisah dengan orang tua tanpa kesulitan ada 6 anak yang mendapatkan bintang 4 dan 1 anak mendapatkan bintang 1. Meminta bantuan jika benar-benar diperlukan ada 4 anak yang mendapatkan bintang 4, untuk bintang 3 ada 1 anak, dan bintang 2 ada 2 anak. Anak mendapat bintang 4 anak dapat melakukannya dengan baik, bintang 3 anak mampu melakukannya dengan 1 kali bantuan, bintang 2 anak mampu melakukannya dengan 2 kali bantuan dan bintang 1 anak belum mau melakukannya. Jadi pada indikator menunjukkan sikap positif terhadap diri sendiri dan orang lain ada 1 anak yang masih memerlukan motivasi dan bantuan.

d. Pemahaman tentang disiplin

$$
\text { Pada }
$$
indikator pemahaman tentang disiplin dalam butir menaati aturan bermain ada 4 anak yang mendapatkan bintang 4, 2 anak mndapatkan bintang 3 dan 1 anak mendapatkan bintang 1. Pada butir cara mengatur diri sendiri ada 4 
anak yang mendapatkan 4 bintang, 1 anak mendapatkan bintang 3, 1 anak lagi mendapatkan bintang 2 dan 1 . Anak mendapatkan bintang 4 berarti anak dapat disiplin dengan baik, bintang 3 anak mampu disiplin dengan motivasi, bintang 2 anak mampu disiplin dengan bantuan dan bintang 1 anak belum disiplin. Jadi pada indikator pemahaman tentang disiplin sebagian besar anak sudah disiplin dengan baik.

Berdasarkan hasil penelitian dari keempat indikator perkembangan sosial banyak anak yang mendapatkan bintang 4. Jadi pada perkembangan sosial kelompok B di TK Lasiyam kota Surabaya sudah bagus dalam perkembangan sosialnya.

\section{KESIMPULAN}

Berdasarkan hasil penelitian yang telah dilakukan dan pembahasan yang telah dipaparkan penulis, maka diperoleh kesimpulan bahwa full day school memiliki peranan penting dalam perkembangan sosial pada anak. Subjek penelitian adalah murid kelompok B usia 5-6 tahun di TK Lasiyam Kota Surabaya, Objek dalam penelitian ini adalah perkembangan sosial anak usia 5-6 tahun yang dimana dalam perkembangan sosial anak memiliki sikap tanggung jawab, mandiri, disiplin dan berani kesekolah sendiri.
Perkembangan sosial anak usia 5-6 tahun kelompok B di TK Lasiyam Kota Surabaya tersebut dikatakan cukup meningkat dalam sistem pelaksaan full day school yang dimana dalam sistem tersebut mengajarkan pada pembiasaan sehari-hari yang ada disana terutama pada perkembangan sosialnya seperti dalam hal tanggung jawab, mandiri dan disiplinannya. Pengaruh yang besar dan pembiasaan sehari-hari yang diberikan oleh guru kepada murid dalam perkembangan sosial dan perilaku sosialnya.

Pada sistem ini anak tidak juga diajarkan pada pembelajaran seperti sekolah lain, dan disini juga diberikan muatan pengetahuan tentang agama seperti mengaji, dalam full day school ini anak diajarkan dalam melatih dan meningkatkan perkembangan sosial pada anak usia 5-6 tahun yang dimana perkembangan sosial anak dalam lingkup full day school memiliki kemajuaan yang seknifikan dalam hal melatih kemandirian seperti melakukan hal-hal sendiri tanpa harus diarahkan, tidak tergantung dengan orang lain, untuk tanggung jawabnya dalam mengambil dan mengembalikan perlengkapan sendiri, serta disiplin dalam hal menaati aturan dalam bermain.

Dukungan dan motivasi serta pembiasaan-pembiasaan yang diberikan oleh guru pada murid terhadap perkembangan sosial anak usia 5-6 tahun memiliki pengaruh yang lebih besar, dimana dalam 
sehari-hari anak berada dalam lingkup sekolah, pengaruh perkembangan sosial yang didapat lebih banyak dari pada lingkup keluarga terutama orang tua. Anak memiliki bersifat meniruh apa yang dilakukan oleh lingkungan yang ada pada sekitarnya. Full day school ini memiliki peranan dalam melatih anak dalam sikap sosial pada diri anak.

Pada sistem full day school di sekolah Lasiyam dimana anak memiliki perkembangan sosial yang bagus, dan terhindar dari pengaruhpengaruh yang buruk pada lingkungan sekitar mereka. Melalui sistem ini meningkatkan dan memberikan perubahan pada perkembangan sosial yang terjadi pada anak usia 5-6 tahun, yang dimana anak diajarkan pada nilainilai arti tanggung jawab pada diri mereka, mandiri dalam memilih kegiatan dan mengatur dirinya sendiri agar menjadi pribadi yang lebih baik.

\section{DAFTAR PUSTAKA}

Lisnawati soapaty, totok Suyanto. 2014.

" Pengaruh Sistem Sekolah Sehari Penuh (Full Day

School Terhadap prestasi Akademik Siswa SMP Jati Agung Sidoarjo". Jurnal Kajian Moral dan Kewarganegaraan. Vol 2(2): hal. 719-733.

Depiyanti, Oci. 2012. "Model Pendidikan Karakter di Islamic Full Day School". Vol 1(3) hal. 210223
Astuti, Marfiah. 2013."Implementasi Program Full Day School sebagai Usaha mendorong Perkembangan Sosial Peserta Didik TK Unggulan Al-Ya'ulu Kota Malang". Vol 1 (2). hal 133 140

Wiyani, Novan Ardy. 2016. Konsep Dasar PAUD. Yogyakarta : Gava Media .2014. Kurikulum Taman kanakkanak.2010.Jakarta.Depdiknas

Santrock, John W. 2007. Perkembangan Anak Edisi Kesebelas. Jakarta : Erlangga Susanto, Ahmad.2011. Perkembangan Anak Usia Dini. Pengantar Dalam Berbagai Aspeknya.

Jakarta: Kencana

Wiyani, Novan. 2016. Konsep Dasar PAUD. Yogyakarta : Gava Media 2017. Modul Pendidikan dan Pelatihan Berjenjang Tingkat Lanjut. 2017. Jakarta.

Depdiknas kota surabaya

Susanto, Ahmad. 2017. Pendidikan Anak Usia Dini (Konsep dan Teori). Jakarta : PT Bumi Aksara Aisyah, Siti. 2011. Perkembangan dan Konsep Dasar Pengembangan Anak Usia Dini. Jakarta :

Universitas Terbuka Desmita.2015. Psikologi Perkembangan. Bandung : PT Remaja Rosdakarya Gohny, M. Djunaidi \& Alamanshur Fauzan. 2012. Metode Penelitian Kualitatif. Jogjakarta: Ar-

Ruzz Media

Moleong, Lexy.2012. Metode Penelitian Kualitatif. Bandung: PT. Remaja

Rosdakarya.

Susanto,Ahmad: 2011. Perkembengan Anak Usia Dini. Jakarta: Kencana Rahayu, Ribut. 2015. Penerapan Metode Bermain Peran Sebagai Upaya Meningkatkan

Kemampuan Sosial Emosional Pada Anak Kelompok A TK Aisyiyah 05 Surabaya. Tesis tidak 
KEBIJAKAN FULL DAY SCHOOL TERHADAP PERKEMBANGAN SOSIAL ANAK USIA DINI DI TK LASIYAM KOTA

dipublikasikan. Surabaya:

Universitas Muhammadiyah Surabaya

John M. Echols \& Hassan Shadily,

Kamus Inggris-Indonesia. Jakarta:

Gramedia PustakaUtama 